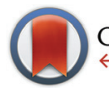

CrossMark

\& click for updates

Cite this: Dalton Trans., 2015, 44

11286

Received 15th May 2015,

Accepted 2nd June 2015

DOI: $10.1039 / c 5 d t 01829 c$

www.rsc.org/dalton

\section{Thermochromism and switchable paramagnetism of cobalt(II) in thiocyanate ionic liquids $\uparrow$}

\author{
Stephen J. Osborne,,$^{\mathrm{a}}$ Sil Wellens, ${ }^{\mathrm{b}}$ Chris Ward, ${ }^{\mathrm{c}}$ Solveig Felton, ${ }^{\star \mathrm{c}}$ \\ Robert M. Bowman, ${ }^{c}$ Koen Binnemans, ${ }^{b}$ Małgorzata Swadźba-Kwaśny, ${ }^{a}$ \\ H. Q. Nimal Gunaratne ${ }^{a}$ and Peter Nockemann*a
}

\begin{abstract}
Temperature-dependent switching of paramagnetism of a cobalt(II) complex is observed in an ionic liquid solution. Paramagnetic and thermochromic switching occur simultaneously due to a reversible change in coordination. This reversible switching is possible in the ionic liquid solution, which enables mobility of thiocyanate anions by remaining mobile at low temperatures and acts as an anion reservoir.
\end{abstract}

Magnetic ionic liquids (MILs) have intrinsic paramagnetic properties that can originate from the cation, the anion or both. ${ }^{1-4}$ These properties derive from MILs containing high effective concentrations of metal centres, which can be transition metals or lanthanides. ${ }^{5,6}$ 1-Methyl-3-butylimidazolium tetrachloroferrate(III), $\left[\mathrm{C}_{4} \mathrm{mim}\right]\left[\mathrm{FeCl}_{4}\right]$, was the first MIL containing magneto-active metal complex anions with antiferromagnetic ordering. ${ }^{7,8}$ Other MIL systems have since been widely investigated., ${ }^{1,9-12}$ While ionic liquid systems with thermochromism related to changes in coordination of the metal centre have previously been reported, this has either been in the presence of additives or molecular solvents, or the magnetic properties were not investigated..$^{13-17}$

Here, we report on solutions of cobalt(II) isothiocyanate in thiocyanate ILs that show reversible switching of the cobalt(II) speciation from tetrahedral $\left[\mathrm{Co}(\mathrm{NCS})_{4}\right]^{2-}$ at room temperature to octahedral $\left[\mathrm{Co}(\mathrm{NCS})_{6}\right]^{4-}$ at temperatures around $233 \mathrm{~K}$. These temperature-dependent changes in the co-ordination environment are accompanied by reversible changes in colour

\footnotetext{
${ }^{a}$ School of Chemistry and Chemical Engineering, The QUILL Research Centre, David Keir Building, Queen's University Belfast, Stranmillis Road, Belfast BT9 5AG, UK. E-mail: p.nockemann@qub.ac.uk

${ }^{b}$ Department of Chemistry, KU Leuven, Celestijnenlaan 200F P.O. Box 2404, B-3001 Leuven, Belgium

${ }^{c}$ Centre for Nanostructured Media, School of Mathematics and Physics, Queen's University Belfast, Belfast, BT7 1NN, UK. E-mail: s.felton@qub.ac.uk $\dagger$ Electronic supplementary information (ESI) available: Additional UV-Vis spectra, SQUID magnetometry data, IR spectra and experimental details. See DOI: $10.1039 / \mathrm{c} 5 \mathrm{dt} 01829 \mathrm{c}$

\$Current address: Atomistic Simulation Centre, School of Mathematics and Physics, Queen's University Belfast, Belfast, BT7 1NN, United Kingdom.
}

(blue to red) and by significant changes of the effective magnetic moment of these fluids. The IL acts as a reservoir for the thiocyanate anions, enabling a reversible equilibrium, which in turn results in a reversible temperature-dependent switching of the coordination environment; hence a reversible switching of the magnetic moment. The main difference to previous studies is that we present a fully self-contained simple ionic liquid thermochromic and magnetically switchable system.

Peppel et al. have reported on stoichiometric compounds of $\left[\mathrm{Co}(\mathrm{NCS})_{4}\right]^{2-}$ ion with either $\left[\mathrm{C}_{2} \mathrm{mim}\right]^{+}$(1-ethyl-3-methylimidazolium) or $\left[\mathrm{C}_{4} \mathrm{mim}\right]^{+}$(1-butyl-3-methylimidazolium) cations, which form bright blue metal-containing ILs with very low glass transition temperatures (around $206 \mathrm{~K}$ ), a relatively low viscosity and an expected paramagnetic behaviour. ${ }^{18}$ However, the solutions of cobalt(II) isothiocyanate in the respective thiocyanate IL, we report here, contain additional mobile thiocyanate anions surrounding the metal complexes; there is thus a large excess of thiocyanate ions with respect to cobalt(II) ions present.

The tetrahedral $\left[\mathrm{Co}(\mathrm{NCS})_{4}\right]^{2-}$ complex that is found in the IL solutions at room temperature and down to $233 \mathrm{~K}$, has a characteristic bright blue colour. UV-Vis absorption spectra of a thin film of the liquid solutions of 1 equivalent of cobalt(II) thiocyanate in 10 equivalents of $\left[\mathrm{C}_{2} \mathrm{mim}\right][\mathrm{SCN}](\mathbf{1})$ and a solution of cobalt(II) thiocyanate in $\left[\mathrm{C}_{4} \mathrm{mim}\right][\mathrm{SCN}](2)$, have been recorded at temperatures ranging from $293 \mathrm{~K}$ to $203 \mathrm{~K}$ (see Fig. 2 for (2); (1) is shown in Fig. 1-ESI†). A high dilution was chosen due to the high absorbance of cobalt(II), even in thin films. The same colour changes can also be observed for more concentrated systems with 1:4 mixtures (equivalents cobalt: equivalents $\mathrm{IL}$ ), but not for $1: 2$ mixtures, nor in other solvents with thiocyanate excess (more information in $\mathrm{ESI}_{\dagger}^{\dagger}$ ).

The UV-Vis absorption spectra of the solutions (1) and (2) at room temperature exhibit a strong absorption band at $630 \mathrm{~nm}$ $\left(15870 \mathrm{~cm}^{-1}\right)$, with a shoulder with weaker absorptions at $618 \mathrm{~nm}\left(16181 \mathrm{~cm}^{-1}\right)$ and $592 \mathrm{~nm}\left(16890 \mathrm{~cm}^{-1}\right)$. These bands correspond to the characteristic transitions of tetrahedral 
$\mathrm{Co}(\mathrm{NCS})_{2}$ dissolved in excess ionic liquid

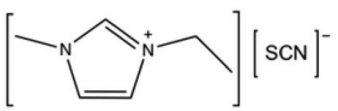

$\left[\mathrm{C}_{2} \operatorname{mim}\right][\mathrm{SCN}]$
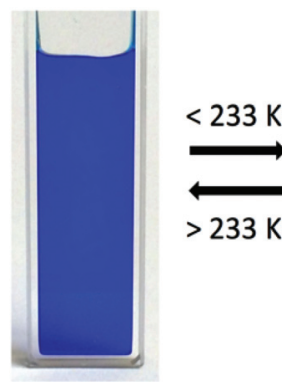

Fig. 1 A solution of cobalt(॥) isothiocyanate, $\mathrm{Co}(\mathrm{NCS})_{2}$, in the ionic liquid (1-ethyl-3-methylimidazolium) thiocyanate, $\left[\mathrm{C}_{2} \mathrm{mim}\right][\mathrm{SCN}](1 \mathrm{~A})$; on the right side, the reversible colour change upon cooling below $233 \mathrm{~K}$ is shown in a $3 \mathrm{~mm}$ cuvette.

cobalt(II) from the ${ }^{4} \mathrm{~A}_{2}$ ground state to the excited states ${ }^{4} \mathrm{~T}_{2}$, ${ }^{4} \mathrm{~T}_{1}(\mathrm{~F})$, and ${ }^{4} \mathrm{~T}_{1}(\mathrm{P})$, in order of increasing energy.

Upon cooling of the IL solution, the coordination of cobalt (II) changes from a tetrahedral to an octahedral environment at $233 \mathrm{~K}$, and the coordinative transition is accompanied by a colour change from bright blue to bright red (see Fig. 1). There is a sole example in the literature that reports on the structural characterisation of an octahedral, bright red $\left[\mathrm{Co}(\mathrm{NCS})_{6}\right]^{4-}$ complex. ${ }^{19}$ The UV-Vis absorption spectra of the six-coordinate octahedral cobalt(II) complexes in (1) and (2) show a weak absorption band with the highest intensity at $472 \mathrm{~nm}$

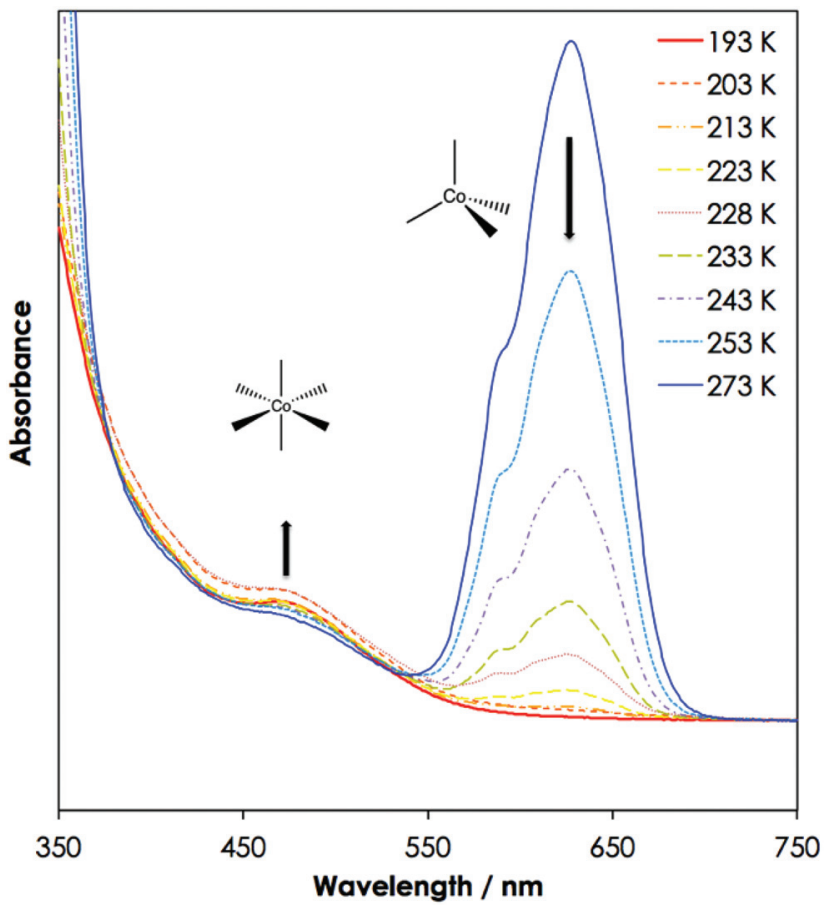

Fig. 2 Temperature-dependent UV-Vis absorption spectra of cobalt(II) thiocyanate dissolved in 1-butyl-3-methylimidazolium thiocyanate, $\left[\mathrm{C}_{4} \mathrm{mim}\right][\mathrm{SCN}]$ (2). The strong absorption band around $630 \mathrm{~nm}$ corresponds to the tetrahedral $\left[\mathrm{Co}(\mathrm{NCS})_{4}\right]^{2-}$, whereas the transition around $472 \mathrm{~nm}$ corresponds to octahedral $\left[\mathrm{Co}(\mathrm{NCS})_{6}\right]^{4-}$.
(21 $180 \mathrm{~cm}^{-1}$ ), which is typical for a Laporte forbidden transition to the ${ }^{4} \mathrm{~T}_{1 \mathrm{~g}}(\mathrm{P})$ state in the presence of an inversion centre.

IR spectra of a solution of cobalt(II) thiocyanate in 10 equivalents of $\left[\mathrm{C}_{2} \mathrm{mim}\right][\mathrm{SCN}](\mathbf{1})$ at room temperature and below $233 \mathrm{~K}$ are shown in Fig. 2-SI and 3-ESI. $\dagger$ At ambient temperature, a strong band at $2060 \mathrm{~cm}^{-1}$ corresponds mainly to the non-coordinating thiocyanate anions as well as to the tetra-coordinate $\left[\mathrm{Co}(\mathrm{NCS})_{4}\right]^{2-}$. Upon cooling, shoulders at 2123 and $2090 \mathrm{~cm}^{-1}$ appear, which can be assigned to the $\mathrm{C}-\mathrm{N}$ stretching frequencies of six-coordinate octahedral cobalt(II), in accordance with reported analogue nickel(II) hexaisothiocyanate complexes. ${ }^{20}$ Changes in the S-C stretching vibration region upon cooling are less distinct with a disappearing band at $880 \mathrm{~cm}^{-1}(\mathrm{w})$ and a shift from $747(\mathrm{w})$ to $753 \mathrm{~cm}^{-1}(\mathrm{w})$.

The effective magnetic moment that Peppel et al. reported for the $\left[\mathrm{Co}(\mathrm{NCS})_{4}\right]^{2-}$ ion in the $\left[\mathrm{C}_{4} \mathrm{mim}\right]^{+}$ILs is $\mu_{\text {eff }}=4.40 \mu_{\mathrm{B}}$ in the range $2-333 \mathrm{~K}$, which is typical for a high-spin cobalt(II) system $\left(S=3 / 2\right.$; spin-only value $\left.\mu_{\text {eff }}=3.87 \mu_{\mathrm{B}}\right) .{ }^{18}$ No change in effective magnetic moment as a function of temperature was reported. In our study, the temperature-dependent magnetisation of solutions of cobalt(II) isothiocyanate in thiocyanate ILs was measured in the range $180 \mathrm{~K}$ to $330 \mathrm{~K}$ by SQUID magnetometry (Fig. 3 and 4-ESI $\dagger$ ).

The ionic liquid acts as a reservoir of thiocyanate anions enabling the reversible coordinative change from tetrahedral to octahedral isothiocyanate environment of cobalt(II). Upon cooling, a change in effective moment is observed from the high-temperature values of 3.4(2) $\mu_{\mathrm{B}}$ and 3.2(2) $\mu_{\mathrm{B}}$ to low temperature values of $\mu_{\mathrm{eff}}=4.5(2) \mu_{\mathrm{B}}$ and $4.0(2) \mu_{\mathrm{B}}$ for samples (1) and (2), respectively.

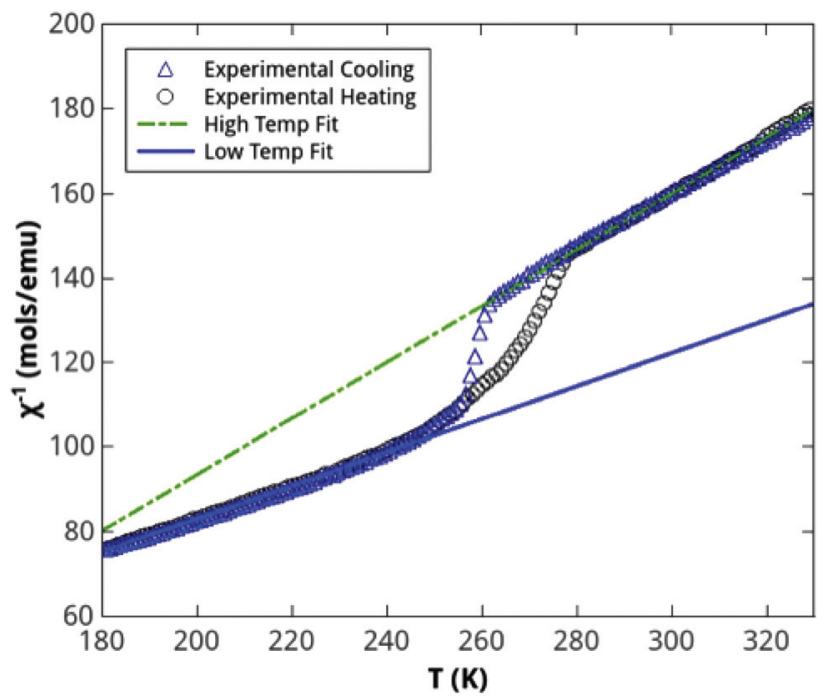

Fig. 3 Magnetic susceptibility measurements for sample (1) in the temperature range from $180 \mathrm{~K}$ to $330 \mathrm{~K}$. The circles and triangles represent the experimental data collected on heating and cooling, and the lines show the Curie-Weiss fits used to determine the effective magnetic moments. 
Heating the samples after cooling reverses the effective magnetic moment changes, with some temperature hysteresis around the transition. This hysteresis is more pronounced for sample (1), which has a sharper transition than sample (2) at approximately $260 \mathrm{~K}$ on cooling. The transition occurs in the region $200-260 \mathrm{~K}$ for sample (2). This gradual transition and the presence of a hysteresis indicate that the change in effective moment is due to a dynamic effect, such as a change in coordination requiring the diffusion of thiocyanate ions to/ from the cobalt(II) ion. The fact that the low temperature effective magnetic moment of sample (2) is slightly smaller than that of sample (1), is attributed to the transition to the octahedral coordination not being realized as fully in the MIL with the $\left[\mathrm{C}_{4} \mathrm{mim}\right]^{+}$cation due to the slightly lower mobility of the $\left[\mathrm{C}_{4} \mathrm{mim}\right]^{+}$cation than the $\left[\mathrm{C}_{2} \mathrm{mim}\right]^{+}$.

The change in coordination from tetrahedral to octahedral is accompanied by an increase in the effective magnetic moment for both samples, as is expected from theoretical calculations of the effective magnetic moment of $\mathrm{Co}$ (II) in different ligand fields. ${ }^{21}$ This change is different to that seen in spin crossover complexes, ${ }^{22}$ where the transitions occur between high-spin and low-spin states, often also involving a transition from para- to diamagnetism.

In the two ionic liquids discussed here both the high and low temperature states are paramagnetic with the change in effective magnetic moment reflecting the difference in orbital splitting, $\Delta$ between the different coordination states, which governs the departure from the spin-only moment (see Fig. 4). The change in effective magnetic moment between the high and low temperature states for the current samples could not be explained by a transition to a low-spin tetrahedral state, since a decrease in effective magnetic moment would be expected in that case.

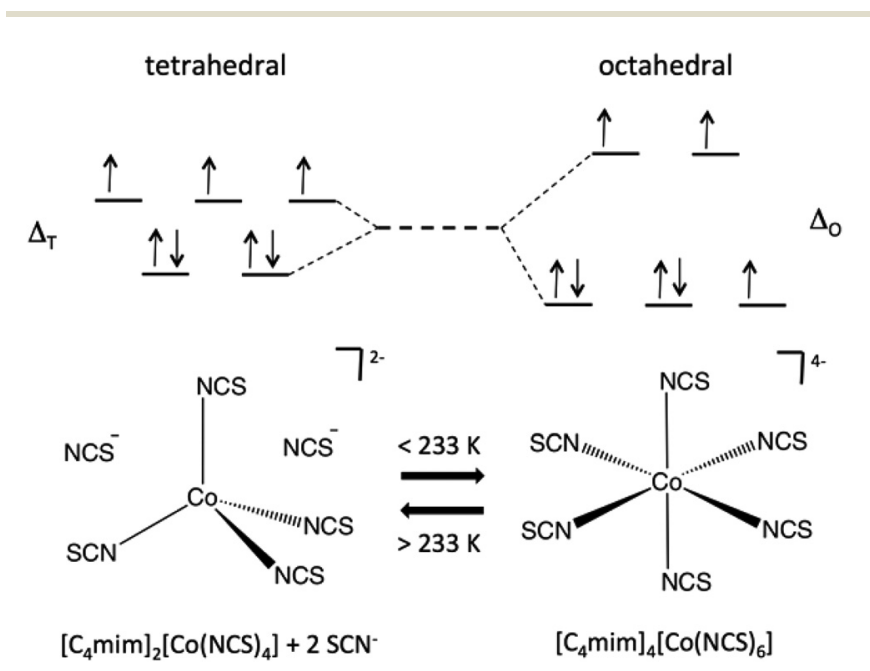

Fig. 4 Coordinative equilibrium between the high-temperature tetrahedral (left) and low-temperature octahedral (right) environment of cobalt(II) in the thiocyanate ILs. The orbital splitting and electron distribution for the tetrahedral and octahedral coordination is shown at the top.

\section{Conclusions}

Solutions of cobalt(II) isothiocyanate in 1-alkyl-3-methyl-imidazolium thiocyanate ILs show reversible switching of the coordination of cobalt(II) from a tetrahedral $\left[\mathrm{Co}(\mathrm{SCN})_{4}\right]^{2-}$ environment at ambient temperature to an octahedral [Co $\left.(\mathrm{SCN})_{6}\right]^{4-}$ coordination at temperatures below $230 \mathrm{~K}$. This temperature-dependent change in coordination is correlated with a reversible change in colour (blue to red), showing typical UV-Vis spectral transitions for tetrahedral and octahedral coordination. The most prominent consequence is reversible switching of the effective magnetic moment in such ionic liquid solutions. The observed equilibrium between the two coordination modes can be interpreted in terms of an entropic effect. This effect is also cation-dependent and has only been observed for imidazolium cations, whereas larger phosphonium cations such as $\left[\mathrm{P}_{666(14)}\right]^{+}$do not feature this behaviour, and even small changes such as an ethyl/butyl chain on the cation results in major differences in behaviour. The ILs provide a reservoir for the anions, that enables mobility of the thiocyanate anions in the liquid state over a wide temperature range. The system studied here are fully self-contained simple ionic liquid systems, where paramagnetic and thermochromic switching occur simultaneously due to a reversible change in coordination of the Co(II) centre. This observation could pave the way towards novel stimuli-responsive self-contained, non-volatile liquid materials.

\section{Acknowledgements}

P.N. and S.F. thank the Royal Society for a Research Grant (RG130739). This research was supported by the Flemish Institute for the Promotion of Innovation by Science and Technology (IWT Vlaanderen) via a Baekeland PhD fellowship to Sil Wellens (IWT 090272) and by Umicore Group Research. The authors also acknowledge financial support by the FWO-Flanders (Research Community "Ionic Liquids"). We thank Seagate Technology (Ireland) for their financial support to establish ANSIN (http://www.ansin.eu).

\section{Notes and references}

1 A. Branco, L. C. Branco and F. Pina, Chem. Commun., 2011, 47, 2300-2302.

2 R. E. Del Sesto, T. M. McCleskey, A. K. Burrell, G. A. Baker, J. D. Thompson, B. L. Scott, J. S. Wilkes and P. Williams, Chem. Commun., 2008, 447-449.

3 S. A. Kozlova, S. P. Verevkin, A. Heintz, T. Peppel and M. Kockerling, J. Chem. Eng. Data, 2009, 54, 1524-1528.

4 Z. L. Xie and A. Taubert, ChemPhysChem, 2011, 12, 364368.

5 B. Mallick, B. Balke, C. Felser and A. V. Mudring, Angew. Chem., Int. Ed., 2008, 47, 7635-7638. 
6 P. Nockemann, B. Thijs, N. Postelmans, K. Van Hecke, L. Van Meervelt and K. Binnemans, J. Am. Chem. Soc., 2006, 128, 13658-13659.

7 I. de Pedro, D. P. Rojas, J. A. Blanco and J. R. Fernandez, J. Magn. Magn. Mater., 2011, 323, 1254-1257.

8 Q. G. Zhang, J. Z. Yang, X. M. Lu, J. S. Gui and Z. Huang, Fluid Phase Equilib., 2004, 226, 207-211.

9 Y. Yoshida and G. Saito, Phys. Chem. Chem. Phys., 2010, 12, 1675-1684.

10 A. Garcia-Saiz, I. de Pedro, J. A. Blanco, J. Gonzalez and J. R. Fernandez, J. Phys. Chem. B, 2013, 117, 3198-3206.

11 S. Hayashi, S. Saha and H. O. Hamaguchi, IEEE Trans. Magn., 2006, 42, 12-14.

12 J. L. Wang, H. W. Yao, Y. Nie, X. P. Zhang and J. W. Li, J. Mol. Liq., 2012, 169, 152-155.

13 N. Aoyagi, K. Shimojo, N. R. Brooks, R. Nagaishi, H. Naganawa, K. Van Hecke, L. Van Meervelt, K. Binnemans and T. Kimura, Chem. Commun., 2011, 47, 4490-4492.

14 C. D. Gu and J. P. Tu, RSC Adv., 2011, 1, 1220-1227.
15 N. Banic, M. Vranes, B. Abramovic, J. Csanadi and S. Gadzuric, Dalton Trans., 2014, 43, 15515-15525.

16 Y. Kohno, M. G. Cowan, M. Masuda, I. Bhowmick, M. P. Shores, D. L. Gin and R. D. Noble, Chem. Commun., 2014, 50, 6633-6636.

17 Y. Funasako, T. Mochida, K. Takahashi, T. Sakurai and H. Ohta, Chem. - Eur. J., 2012, 18, 11929-11936.

18 T. Peppel, M. Kockerling, M. Geppert-Rybczynska, R. V. Ralys, J. K. Lehmann, S. P. Verevkin and A. Heintz, Angew. Chem., Int. Ed., 2010, 49, 7116-7119.

19 T. N. Mali, R. D. Hancock, J. C. A. Boeyens and E. L. Oosthuizen, J. Chem. Soc., Dalton Trans., 1991, 11611163.

20 D. Forster and D. M. L. Goodgame, Inorg. Chem., 1965, 4, 823-829.

21 H. Lueken, Magnetochemie: Eine Einführung in Theorie und Anwendung, Vieweg \& Teubner Verlag, Stuttgart, Leipzig, 1999.

22 M. Okuhata, Y. Funasako, K. Takahashi and T. Mochida, Chem. Commun., 2013, 49, 7662-7664. 